\title{
Engineering a path to relinquishment: an Australian case study in ecological conservation
}

\author{
R Marten BHP, Australia \\ C Bagnall BHP, Australia
}

\begin{abstract}
Achieving relinquishment of residual environmental and other liabilities post-closure poses a key challenge for mining and heavy industry alike. Since closure of the Newcastle Steelworks (Steelworks) in 1999, BHP has implemented a range of projects to remedy a legacy from 85 years of steelmaking. Of these projects, the fiveyear Hunter River Remediation Project (HRRP)-completed in 2012-has been the most substantial undertaking and represents the largest clean-up project of its kind completed in Australia. At its conclusion, and for the quality of its work, the HRRP was recipient of national environmental and engineering excellence awards.

In delivering the HRRP, BHP made a firm commitment to restoring areas impacted by the Steelworks whilst preventing as far as practical any new impacts arising from remediation works.

As part of the HRRP, the construction of a purpose-built, lined emplacement facility on former Steelworks land was required to dispose of over $800,000 \mathrm{~m}^{3}$ of cement-stabilised river sediment. Whilst on disturbed industrial land, the construction footprint of this facility extended over habitat of the endangered green and golden bell frog (Litoria aurea). This species had colonised ponded areas within the industrial site, perhaps after the cessation of Steelworks activities.

BHP's response was to go back to 'first principles' to minimise its potential to cause impacts to this species. With no other feasible locations to receive this volume of treated sediment, BHP implemented a comprehensive process to re-assess its original emplacement facility design. This work ultimately conserved 90\% of the local breeding habitat and, additionally, new habitat was created in nearby areas. BHP has recorded successive breeding events in the new habitat, contributing to a significant increase in the species' local population. In addition to the ecological benefits, the facility redesign materially reduced the complexity and associated time frame and costs of the regulatory approvals needed to commence the major remediation works.
\end{abstract}

This paper will discuss the key aspects of BHP's design and execution approach to minimise its ecological footprint whilst engineering a feasible path to the relinquishment of related liabilities.

Keywords: Newcastle Steelworks, Hunter River remediation project, green and golden bell frog, Litoria aurea, compensatory habitat program

\section{$1 \quad$ Introduction}

Achieving relinquishment of residual environmental and other liabilities post-closure poses a key challenge for mining and heavy industry alike.

In the early 1900s, and primarily attributable to the onset of World War I, the demand for a large-scale iron and steel industry in Australia was becoming apparent. In response, Broken Hill Proprietary Ltd, or BHP, made the transition into the steelmaking industry. Newcastle, a large coastal city in the state of New South Wales (NSW), was the site of choice for the Steelworks, owing to its suitable harbour, ready labour, proximity to the coal mines of the Hunter Valley, and BHP's ownership of a small parcel of land, which would become the nucleus of the BHP Newcastle Steelworks site. 
The Newcastle Steelworks officially opened on 2 June 1915, and at its peak was the largest steelworks in the Commonwealth. BHP operated the Newcastle Steelworks adjacent to the South Arm of the Hunter River from 1915 until closure in 1999.

During its operations, when environmental standards were not what they are today, contamination primarily in the form polycyclic aromatic hydrocarbons found their way into the riverbed sediments adjacent to the Steelworks site. At the time of closure, BHP identified the likelihood of contamination in the riverbed sediments, and the need for clean-up. This notification was made in accordance with the NSW Contaminated Land Management Act 1997. The NSW Environment Protection Authority supported this position, and the early phases of the Hunter River Remediation Project (HRRP) were then initiated.

A significant component of the HRRP was the construction of a purpose-built emplacement facility on former Steelworks land at Kooragang Island (this site was formerly used for waste disposal of Steelworks byproducts). The new, lined facility was required for the disposal of over $800,000 \mathrm{~m}^{3}$ of cement-stabilised river sediment. Although located on disturbed industrial land, threatened species assessments established that the original construction footprint proposed would extend over large areas of local habitat of the endangered green and golden bell frog (Litoria aurea), which had colonised many ponded areas within the heavily modified landscape.

With no other suitable and feasible alternate locations within the local region to receive this volume of treated sediment, and with a new project team having been assembled by BHP in 2007 to reappraise the planning to date, BHP decided to critically re-assess its original emplacement facility design to further minimise its potential impacts to the environment. BHP recognised the significance of this habitat to the local survival of this endangered species and sought a better outcome, both immediate and long-term, between development and conservation. If successful, this approach would also produce added benefits to simplify what had already become a large and complex regulatory approvals framework and to reduce the scope of any future environmental offset (and in doing so also reduce the time and costs until relinquishment was achieved).

BHP's response was to go back to 'first principles' to minimise its potential to cause impacts to $L$. aurea, and other threatened species and endangered ecological communities (EEC). Following a three month evaluation process on a time critical project, a novel and substantial redesign of the entire emplacement facility and related disturbance ultimately conserved around $90 \%$ of the local aquatic habitat of this species. This habitat was identified from studies as having the potential to support breeding and foraging of $L$. aurea, and the wading and foraging habitat of some threatened bird species. The original design, which had been previously accepted 'in principle' by many relevant regulatory authorities, would have removed the majority of this key habitat type.

Construction of the emplacement facility was on the 'critical path' for the HRRP works schedule. In addition to minimising the ecological footprint, the facility redesign materially reduced the complexity and associated time frame and costs of the regulatory approvals needed to commence the major remediation works. Minimising habitat disturbance also reduced, on a relative scale, BHP's compensatory offset habitat requirements for $L$. aurea, which was a core component of BHP's compensatory habitat program (CHP) to secure regulatory approvals of the works. The latter is important, and relevant to this paper, as it demonstrates the added strategic value in undertaking a re-evaluation of this kind with relinquishment in mind.

BHP made a conscious decision to front-end load its CHP, and implement a comprehensive early research and monitoring program that included the construction of trial habitat to inform the design of subsequent full-scale habitat. This approach has proven to be successful, as demonstrated by the recording in 2016/2017 of successive annual breeding events of $L$. aurea within the new compensatory habitat, contributing to a significant increase in the species' local population and within an expanded area in the locale.

This paper will discuss the key aspects of BHP's design and execution approach, which was implemented to: 
- Minimise its ecological footprint to the practical extent possible, and to not put at risk, or create a tipping point, for the local survival of the L. aurea.

- Optimise the likelihood of delivering a successful L. aurea CHP to enhance the conservation outcomes and project legacy, whilst minimising the time until relinquishment.

\section{$2 \quad$ Hunter River Remediation Project}

The HRRP was a large, complex environmental remediation project undertaken in the South Arm of the Hunter River, Newcastle. Its primary objective was the clean-up of river sediments contaminated by activities of the former BHP Newcastle Steelworks, which operated from 1915 until 1999.

The HRRP - completed in 2012-was, at the time, the largest remediation project of its kind to be undertaken in Australia. It was a critical final phase in the massive undertaking to close the entire Steelworks complex that had occupied hundreds of hectares at Newcastle Port. The project involved dredging of river sediment, treatment of the contaminated sediment using a proven and approved cement stabilisation process, transport of the contaminated sediment by road, and emplacement of the treated sediment in a purposebuilt lined emplacement facility. An image of the HRRP dredging and operations is included as Figure 1.

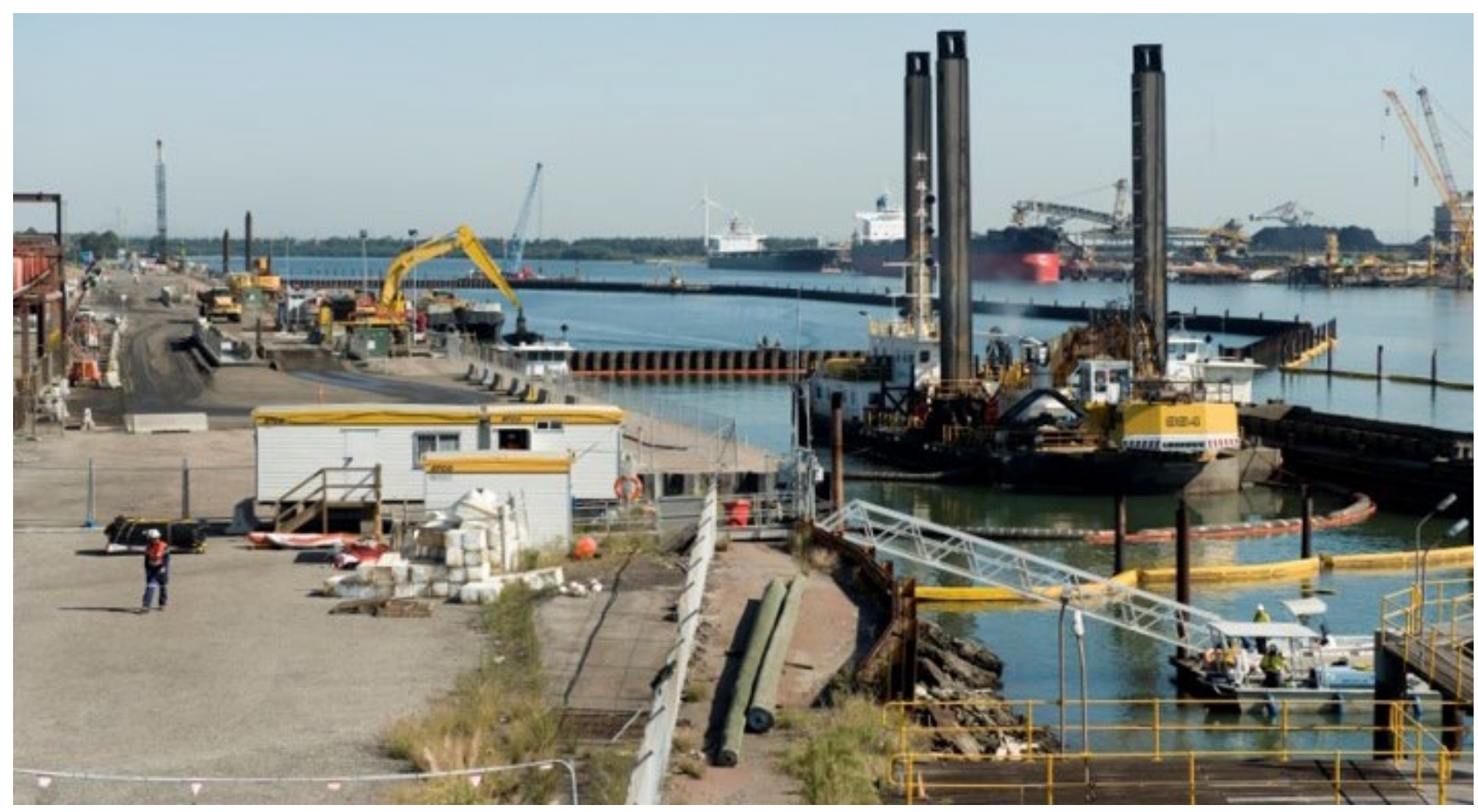

Figure 1 Dredging (circa November 2010) operations within the South Arm of the Hunter River (foreground), and barge unloading operations prior to treatment of sediment (background)

The detailed design of the emplacement facility was progressed during the HRRP Definition Phase Study (DPS). During the DPS, the preliminary design was deemed unfeasible by BHP due primarily to its environmental impact, namely the extent of potential impacts to threatened species habitat (primarily L. aurea), and secondly the significant regulatory approval delays the original design would incur impacting works.

The potential approval delays were a key consideration at the time. The schedule imperative of the HRRP was attributable in part to the fact that the river owner, the State Government (Roads and Maritime NSW), required timely removal of the contaminated sediment (as part of the HRRP) in order to facilitate increased Port development important to the NSW State economy.

The HRRP was successfully delivered by BHP, with the project's environmental and overall performance acknowledged via the receipt of the following prestigious awards: 
- United Nations Association of Australia 'World Environment Day Environmental Best Practice Program (2011)'.

- Hunter Business Chamber 'Contribution to the Region (2011)'.

- National Safety Council of Australia 'Excellence in Innovative Environmentally Sustainable Work Practices (2011)'.

- BHP Billiton 'Environmental Excellence (2011)'.

- Engineers Australia 'Engineering Innovation - Newcastle Division (2012)'; 'Engineering Excellence Newcastle Division (2012)'.

\section{Methodology - emplacement facility}

\subsection{Mitigating key risks in design}

Prior to the HRRP, the site of the Kooragang Island Emplacement Cell (KIEC) facility construction was within a highly modified industrial landscape of generally degraded condition, with no identified land use. It featured water bodies (i.e. ponds) that had formed over time from receiving rainfall/surface water runoff and potentially shallow groundwater. The artificial condition of the site was due to its legacy of use from 1972 to 1999 as an authorised waste disposal ground for byproducts and industrial waste materials generated from the former Newcastle Steelworks. The site formed part of properties transferred, under formal agreement, from BHP to the NSW Government in 2002.

During the HRRP selection phase study, the emplacement of treated sediment in a purpose-built lined emplacement facility was determined to be the preferred remediation approach. With no other feasible locations in the local area to receive an estimated $800,000 \mathrm{~m}^{3}$ of treated sediment, the former industrial waste facility on Kooragang Island was, subject to receipt of landowner and regulatory approvals, established as the location to construct the emplacement facility.

During the DPS, BHP evolved the design of the KIEC facility in order to minimise the area of potential threatened species habitat disturbed. As part of this process of design evolution, BHP obtained robust ecological baseline data via additional ecological field surveys, and consulted with a range of key stakeholders within government and community, including The University of Newcastle (UoN), Hunter Bird Observers Club, and the NSW State Government landowner representative (at the time, Newcastle Port Corporation). This feedback was additional to the statutory environmental, engineering and other design criteria that were applicable to the KIEC facility, and which in some cases conflicted with or constrained the development of a more ecologically sustainable emplacement design. An example of the latter was the requirement to build the emplacement facility above the highest recorded groundwater level, that inherently meant a larger disturbance footprint was typically required to achieve this because of the height restrictions applicable at the site (to satisfy visual amenity and final land use criteria).

Whilst the process involved additional upfront investment in terms of time, effort and cost, it was deemed necessary to meet BHP Charter values, and minimise the potential for lengthy delays associated with the original design.

Sustainability principles underpinned all aspects of engineering design of the KIEC facility, with the final design resulting in a distinct, non-uniform kidney-shape to 'work around' and protect threatened species habitat, to the practical extent possible. An aerial image of the KIEC facility during construction is included as Figure 2. 


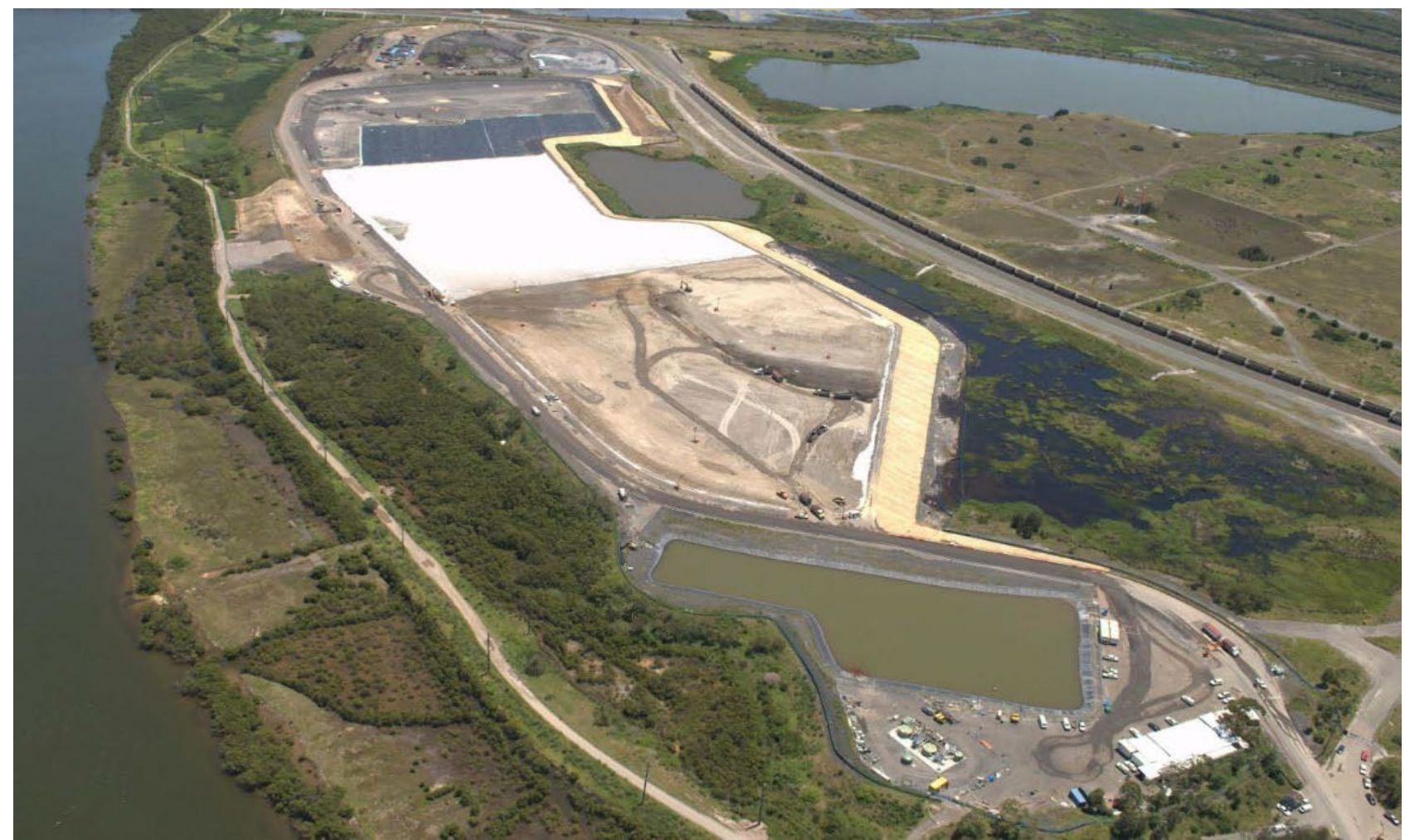

Figure 2 Construction (circa November 2010) of the emplacement facility at Kooragang Island

\subsection{Minimising ecological footprint during construction}

Efforts to minimise the overall footprint of impact from construction of the KIEC continued during the HRRP execution phase, with tight control measures implemented throughout construction. These control measures included pre-clearances of any proposed disturbance areas to check for and allow natural movement away of any $L$. aurea individuals found; avoiding where practical ground disturbance during the $L$. aurea breeding season; installing sediment controls around disturbance areas to protect remaining aquatic habitat for L. aurea; and ensuring the area disturbed was the minimum that was practically required to support the emplacement activities.

\section{Methodology: compensatory habitat program}

\section{$4.1 \quad$ L. aurea status}

Recent research (White \& Pyke 1996, 2008; Mahony 1999) found that since the 1960s L. aurea has undergone a widespread range contraction in NSW with the extinction of over $90 \%$ of populations, primarily from the inland portion of their range.

Information supplied by the NSW Government Office of Environment \& Heritage (2019) lists L. aurea as 'Endangered' in NSW under the Biodiversity Conservation Act 2016 (NSW Government 2016), and information supplied by the Australian Government Department of the Environment and Energy (2019) lists L. aurea as 'Vulnerable' at the Commonwealth level under the Environment Protection Biodiversity Conservation Act 1999 (Australian Government 1999).

A publication by the NSW Department of Environment and Climate Change (DECC) (2007) acknowledges the following as 'key threats' to the extant Kooragang Island population of $L$. aurea:

- Loss of habitat.

- Saline inundation. 
- Introduced predators, including the Plague Minnow (Gambusia holbrooki).

- Chytridiomycosis (Amphibian chytrid fungus disease).

- Introduced plants.

- Water quality.

\subsection{Compensatory habitat program}

BHP was required to develop and implement a CHP as a condition of consent for NSW and Commonwealth approvals, to offset impacts to $L$. aurea arising from development of the KIEC facility. BHP's CHP has a 25 year term commencing in 2010, and extending until 2035.

BHP engaged extensively with a range of stakeholders during CHP development in order to optimise the opportunities for the creation of 'successful' compensatory habitat for $L$. aurea. These stakeholders included the Amphibian Research Laboratory at the UoN, and a technical advisory panel (TAP) in addition to the relevant key NSW and Commonwealth regulatory authorities. The UoN comprised a team with extensive experience in $L$. aurea research on Kooragang Island and the broader region. The TAP was established by BHP following an intensive identification and selection process, as an independent panel comprised of three experts with specialist experience in $L$. aurea research and conservation ecology.

The overall objective of the CHP is to achieve an 'improve or maintain' outcome for L. aurea, which is being delivered through the following primary CHP elements:

1. Completion of a research and monitoring (R\&M) program to enhance the level of understanding of factors that contribute to the long-term survival of the $L$. aurea.

2. Provision of compensatory habitat for $L$. aurea - at a ratio of $2: 1$ to the area of habitat disturbed at the KIEC site - at Ash Island within the Hunter Wetlands National Park (HWNP).

3. Implementation of a monitoring, maintenance and reporting regime for the balance of the CHP term, within the 2.6 ha of compensatory breeding habitat and surrounding 60 ha of terrestrial habitat.

In order to measure and assess the success of the CHP, namely that of the compensatory habitat for L. aurea, key performance indicators (KPIs) were developed in conjunction with the UoN and the TAP, and were subsequently approved by NSW and Commonwealth regulatory authorities. The approved primary KPIs applicable for BHP's CHP are listed in Table 1.

Table 1 Compensatory habitat - primary key performance indicators

\begin{tabular}{ll}
\hline $\begin{array}{l}\text { Primary key performance } \\
\text { indicators }\end{array}$ & Definition \\
\hline $\begin{array}{l}\text { Establishment of a } \\
\text { breeding population }\end{array}$ & $\begin{array}{l}\text { Success = Evidence of natural breeding events in two seasons } \\
\text { (September-March). Such evidence will include presence of eggs, } \\
\text { tadpoles and/or metamorphs that were not released from captive } \\
\text { breeding stock, in at least one pond. The breeding events do not have } \\
\text { to be recorded over two consecutive seasons. }\end{array}$ \\
Establishment of a viable & $\begin{array}{l}\text { Success = Evidence of at least five reproductively-mature individuals } \\
\text { population }\end{array}$ \\
$\begin{array}{l}\text { whin new natural breeding events occurred. Such evidence will include } \\
\text { presence of calling males with nuptial pads and gravid females. }\end{array}$
\end{tabular}

Attainment of both of the primary KPIs within each of two distinct seasons would validate the successful creation of compensatory habitat. 


\subsubsection{Research and monitoring program}

BHP engaged the UoN to develop and implement a comprehensive R\&M program for L. aurea.

The objective of the R\&M program was to enhance the knowledge of factors affecting the survival of $L$. aurea, particularly in the Lower Hunter Region of NSW, and to assist BHP in the creation of successful compensatory habitat. The creation of successful habitat would ultimately assist in securing the future of $L$. aurea in the area, and to support sustainable $L$. aurea populations with the maximum genetic and ecological viability.

The R\&M program, completed in 2015 , was an intensive five-year program which focused on four research priority areas, and specific research objectives within.

As part of the R\&M program, BHP completed a trial program - including the construction of a L. aurea trial habitat site in 2010 - to inform the development of the wider area of compensatory habitat.

The L. aurea trial habitat site (Figure 3) consisted of two identical clusters of ponds constructed adjacent to each other, each containing two deep (1.2 $\mathrm{m}$ below ground surface [bgs]) 'permanent' ponds, and three shallow ( $0.3 \mathrm{~m}-0.5 \mathrm{~m}$ bgs) 'ephemeral' ponds. Specialised frog-exclusion fencing and mesh bird-exclusion netting was installed around one of the clusters of ponds to: a) contain and prevent the movement of frogs beyond the perimeter; and b) limit external influences by preventing the entry of predators (and frogs) from beyond the perimeter.

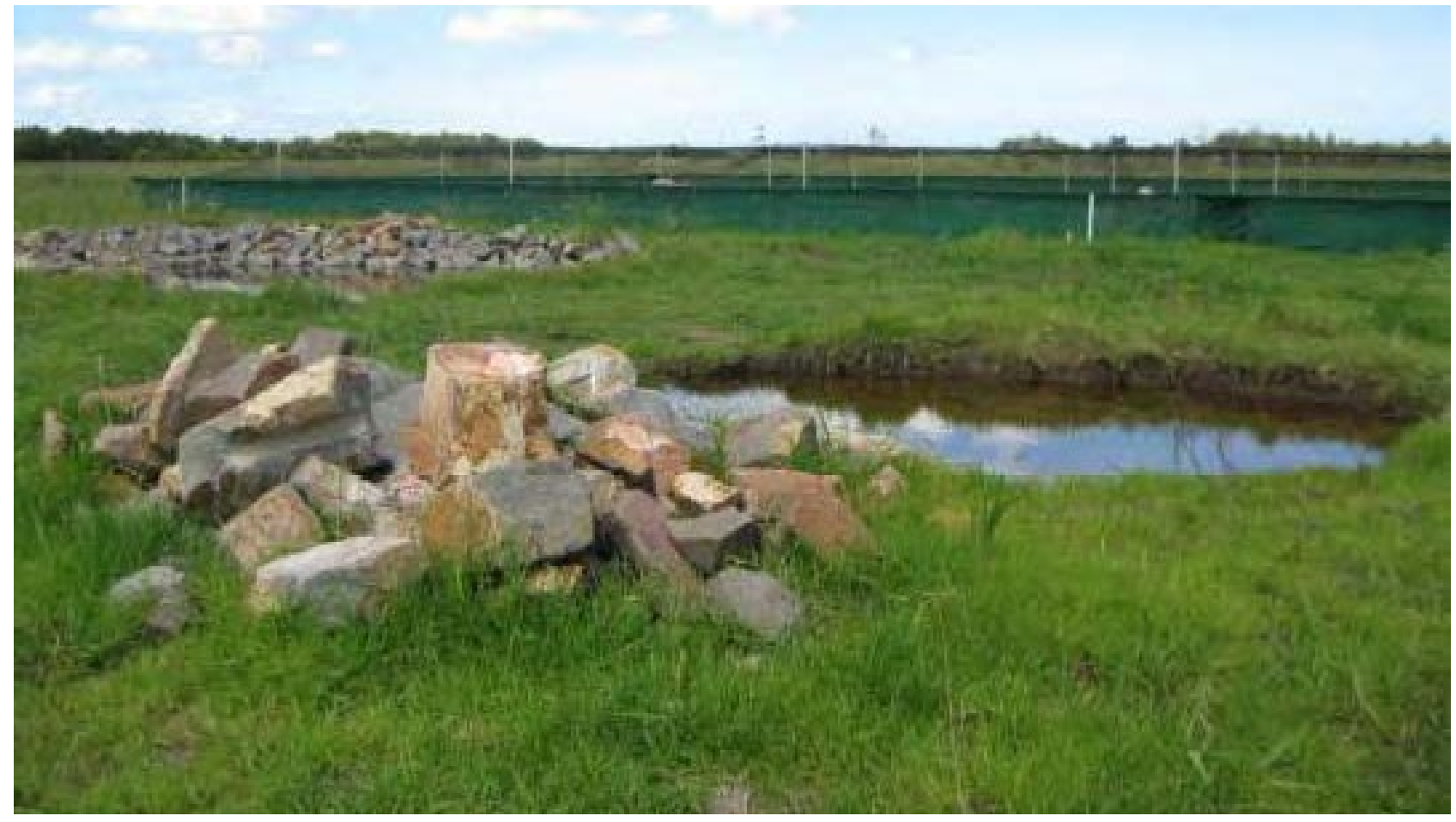

Figure 3 L. aurea trial habitat site (circa November 2010) showing the fenced pond cluster (background) and un-fenced pond cluster (foreground)

During the $2010 / 2011$ and $2011 / 2012$ L. aurea breeding seasons, the L. aurea trial habitat site was populated with approximately 10,000 captively bred tadpoles, metamorphs and juvenile $L$. aurea.

The $L$. aurea trial habitat site was monitored intensively for five years. Monitoring methods consisted of:

- Weekly dip-netting surveys of released tadpoles (until metamorphosing).

- Fortnightly dip-netting of ponds during the L. aurea breeding season (September to March) to detect the presence of $\mathrm{L}$. aurea tadpoles.

- Fortnightly frog nocturnal visual encounter surveys (VES). 
- Monthly frog capture-mark-recapture surveys.

- Hourly monitoring (dataloggers) of pond water temperature.

- Fortnightly monitoring of water levels (depth stick), and water quality variables ( $\mathrm{pH}$, dissolved oxygen, salinity) using a hand-held water quality meter.

Although secondary KPIs (parameters including habitat utilisation, water retention, water quality, emergent vegetation dominance, presence of $G$. holbrooki [mosquito fish]) were met, no $L$. aurea breeding events were recorded within either of the fenced or un-fenced pond clusters, and the primary KPIs were therefore not attained within the trial habitat site.

Another component of the R\&M program involved a long-term landscape utilisation study of $L$. aurea in the Lower Hunter Region of NSW. Historic L. aurea sites in and around the Lower Hunter Region were identified from distribution records and management plans (DECC 2007), and a total of 10 sites, including Kooragang Island, were included in the study. Study research undertaken into habitat features that drive distribution and abundance identified that the following pond characteristics are beneficial to $L$. aurea:

- A high amount of aquatic and terrestrial vegetation.

- A high number of neighbouring permanent ponds.

- High amphibian species and invertebrate taxa diversity.

- Short distance to neighbouring occupied ponds.

- Large pond surface area.

- Absence of G. holbrooki (mosquito fish).

\subsubsection{Compensatory habitat}

The $L$. aurea compensatory habitat site is located within the HWNP adjacent to the South Arm of the Hunter River on Ash Island, NSW. The HWNP is located approximately $8 \mathrm{~km}$ northwest of the Newcastle central business district and within only a few kilometres of the HRRP emplacement site where the original disturbance occurred. The L. aurea trial habitat site is located immediately adjacent to the wider compensatory habitat site.

Two key issues were observed at the L. aurea trial habitat site during monitoring undertaken as part of the R\&M program:

1. Invasion of the predatory exotic fish, G. holbrooki, within six of the 10 trial habitat ponds located within both fenced and un-fenced pond clusters, through connected surface water runoff to surrounding areas during extreme wet weather conditions.

2. Drying of the 'permanent' trial ponds during and after extended periods of dry weather.

These key risks were mitigated in the design of BHP's L. aurea compensatory habitat as follows:

1. Perimeter earth bunds were incorporated into the design of each pond, as a preventative control against the risk of $\mathrm{G}$. holbrooki colonisation via surface water overflow.

2. Permanent ponds were designed to depths greater than those constructed at the $L$. aurea trial habitat site (i.e. greater than $1.2 \mathrm{~m}$ bgs) to allow better connectivity with the underlying groundwater table, thereby maximising the pond hydroperiod during dry conditions.

Connectivity with the underlying groundwater table also had a secondary design intent, noting that low levels of salinity are present within the underlying groundwater table. Levels of salinity over 2 ppt (parts per thousand) have been found to have an inhibitory effect on the chytrid fungus, and significantly increase bell frog survival (Stockwell 2011). 
The potential for invasion and infestation of ponded areas by reed species (e.g. Typha orientalis) and creation of monoculture water bodies was another identified risk, which was actively accounted for during the design phase through diversification of pond designs including depths (i.e. creating a mosaic of permanent ponds and ephemeral ponds), with the deeper areas within the permanent ponds not suitable for reed growth. The mosaic of permanent ponds and ephemeral ponds also served to accommodate, to the extent practical, variations in short and long-term seasonal weather patterns.

The construction of earth bunds around the perimeter of each pond is a distinguishing feature of BHP's L. aurea compensatory habitat site. Whilst the bunding effectively reduced the 'catchment' area, and the potential pond hydroperiod (specifically for ephemeral ponds), it was determined that the benefit of minimising the risk of potential $G$. holbrooki colonisation outweighed the risk of a reduced pond hydroperiod.

Construction of the earth bunds was required to be completed in strict accordance with civil specifications in order to achieve minimum compaction requirements. Notwithstanding the anticipated impact on cost and schedule (excavated material requires significant amounts of material handling to reach required geotechnical properties), the earth bunds were considered a key control measure, and were maintained within the final design.

Overall, the L. aurea compensatory habitat design incorporated, to the extent practical, the pond characteristics identified during the R\&M program as being beneficial to $L$. aurea. The primary intent of the mitigation of key risks in design was to facilitate construction of L. aurea compensatory habitat which functions passively, thereby minimising the likelihood of future liabilities (at or post relinquishment) for BHP and $L$. aurea alike.

BHP's larger L. aurea compensatory habitat (building from the learnings of the R\&M program) was constructed during 2015 (stage 1 - nine ponds) and 2016 (stage 2 - two ponds). The compensatory habitat consists of seven shallow ephemeral ponds, and four deeper permanent ponds, with a combined pond surface area of 2.6 ha. An image of one of BHP's L. aurea compensatory habitat ponds is included as Figure 4.

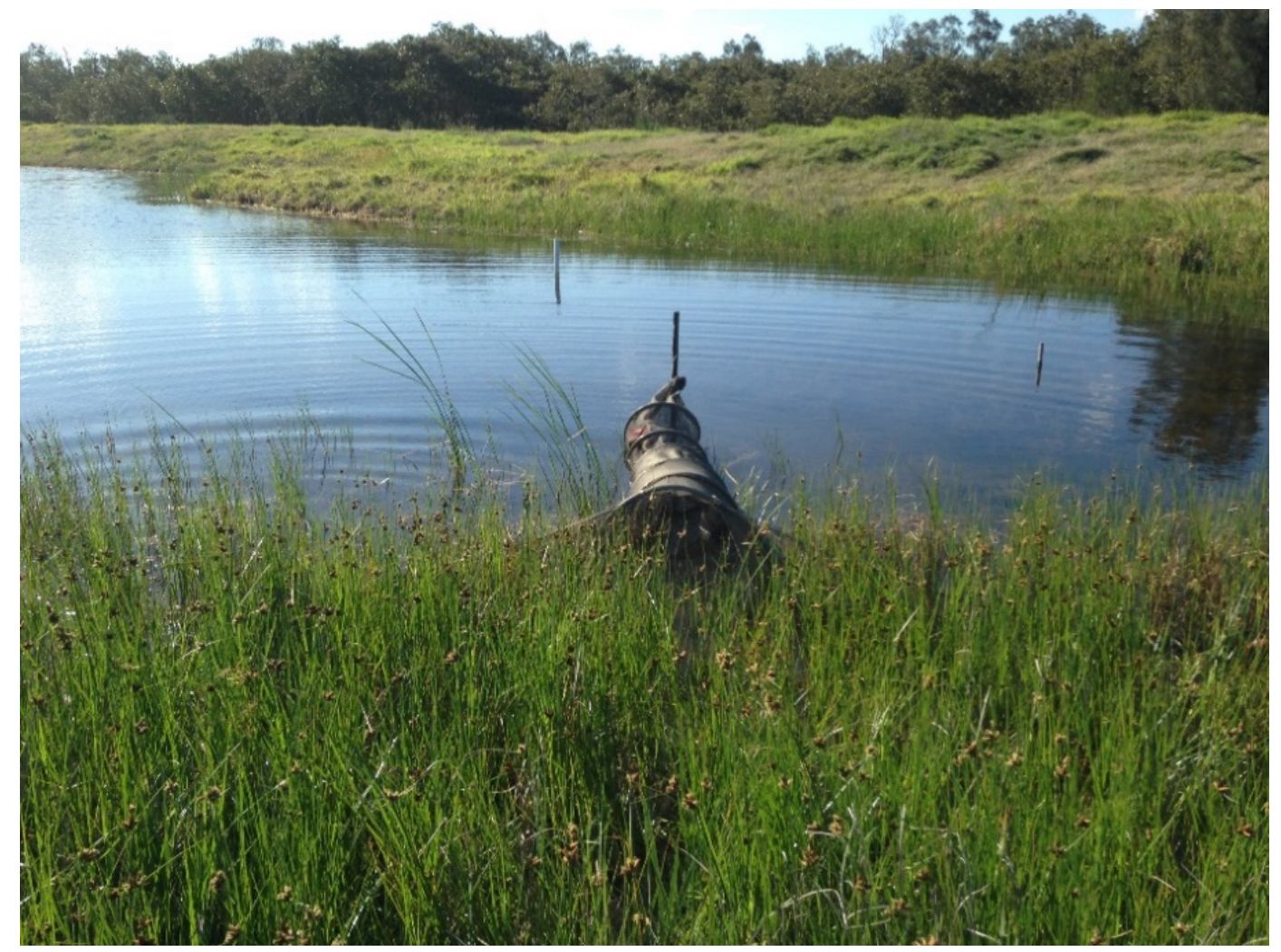

Figure 4 L. aurea compensatory habitat 'permanent' pond (circa September 2018) - elevated perimeter earth bund is visible in the background (a monitoring fyke net is visible in the foreground) 


\section{$5 \quad$ Results and discussion - emplacement facility}

\subsection{Minimisation of ecological footprint through design}

The distinct kidney-shape design of the KIEC facility delivered significant environmental benefit, whilst not compromising fundamental engineering principles.

The design facilitated the conservation of $90 \%$ of local aquatic habitat identified as having the potential to support breeding and foraging of $L$. aurea, and the wading and foraging of threatened bird species. The design also facilitated the conservation of EEC, including $100 \%$ of local mangroves that were able to be avoided from disturbance from a persistent commitment during design, construction and operation of the emplacement facility. Conservation of habitat attained via mitigation of key risks in design is demonstrated in Figure 5.

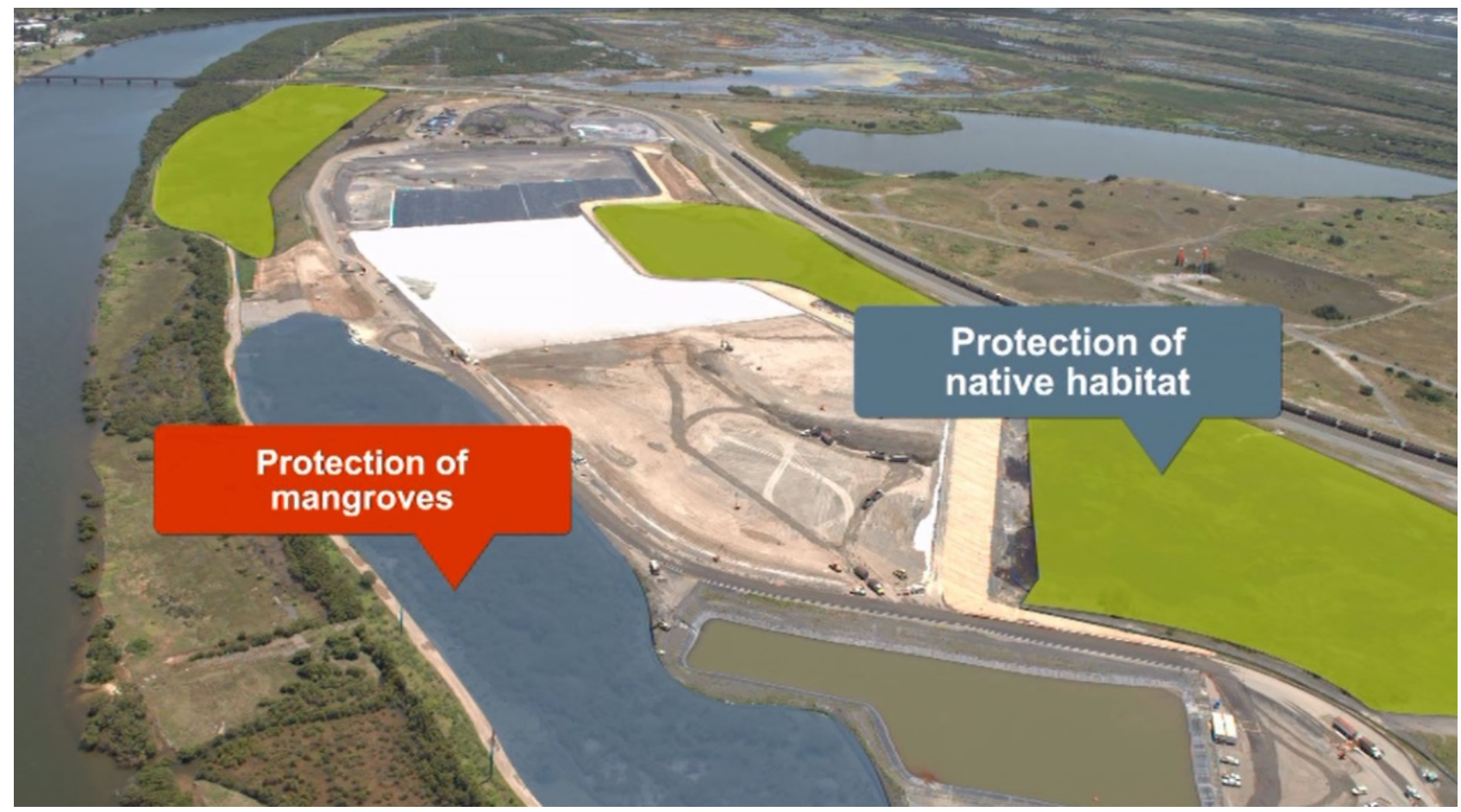

Figure 5 The distinct kidney-shape of the Kooragang Island Emplacement Cell facility conserved 90\% of local aquatic habitat identified as having potential to support breeding and foraging of L. aurea, and $100 \%$ of mangroves

\subsection{Reduction of approvals time frame}

The HRRP was subject to significant regulation and required much interaction with many government departments; 270 approvals were required from 12 Commonwealth, State (NSW) and local government agencies, which generated over 3,400 conditions/actions.

The mitigation of key risks in the final KIEC facility design - attained primarily via the redesign of the emplacement area to minimise the area of potential threatened species habitat directly impacted - had the effect of reducing the time frame for NSW and Commonwealth regulatory approvals by an estimated 12 months. This delivered significant benefits to the HRRP, ultimately enabling, in addition to the primary environmental/ecological benefits, the project to be delivered within the target schedule (and cost), and thereby not impacting upon the schedule of concurrent and future planned new industrial developments (by other proponents) along the South Arm of the Hunter River. 


\subsection{Minimisation of ecological footprint through execution}

Efforts to minimise the overall footprint of impact from the KIEC facility continued during the execution phase, with tight control measures implemented throughout construction. Through these actions and procedures, BHP were able to conserve further areas of habitat that had initially been forecast to be disturbed.

\section{Results and discussion: compensatory habitat program}

Following construction, a comprehensive monitoring program has been implemented within BHP's L. aurea compensatory habitat. Monitoring actions conducted during the L. aurea breeding season include dip-netting, fyke netting, or trapping of tadpoles; VES; auditory surveys; sound recording; and water depth and water quality monitoring.

Key monitoring observations recorded during the 2015-2016 L. aurea breeding season included:

- Mature L. aurea adults were present in the aquatic and riparian habitat within five of the nine constructed ponds.

- Calling by adult males was observed for extended periods during the season.

- Confirmation of a L. aurea breeding event was obtained within one of the nine constructed ponds, with the observation of $L$. aurea tadpoles and metamorphs. An image of a $L$. aurea metamorph captured during the 2015-2016 L. aurea breeding season is included as Figure 6.

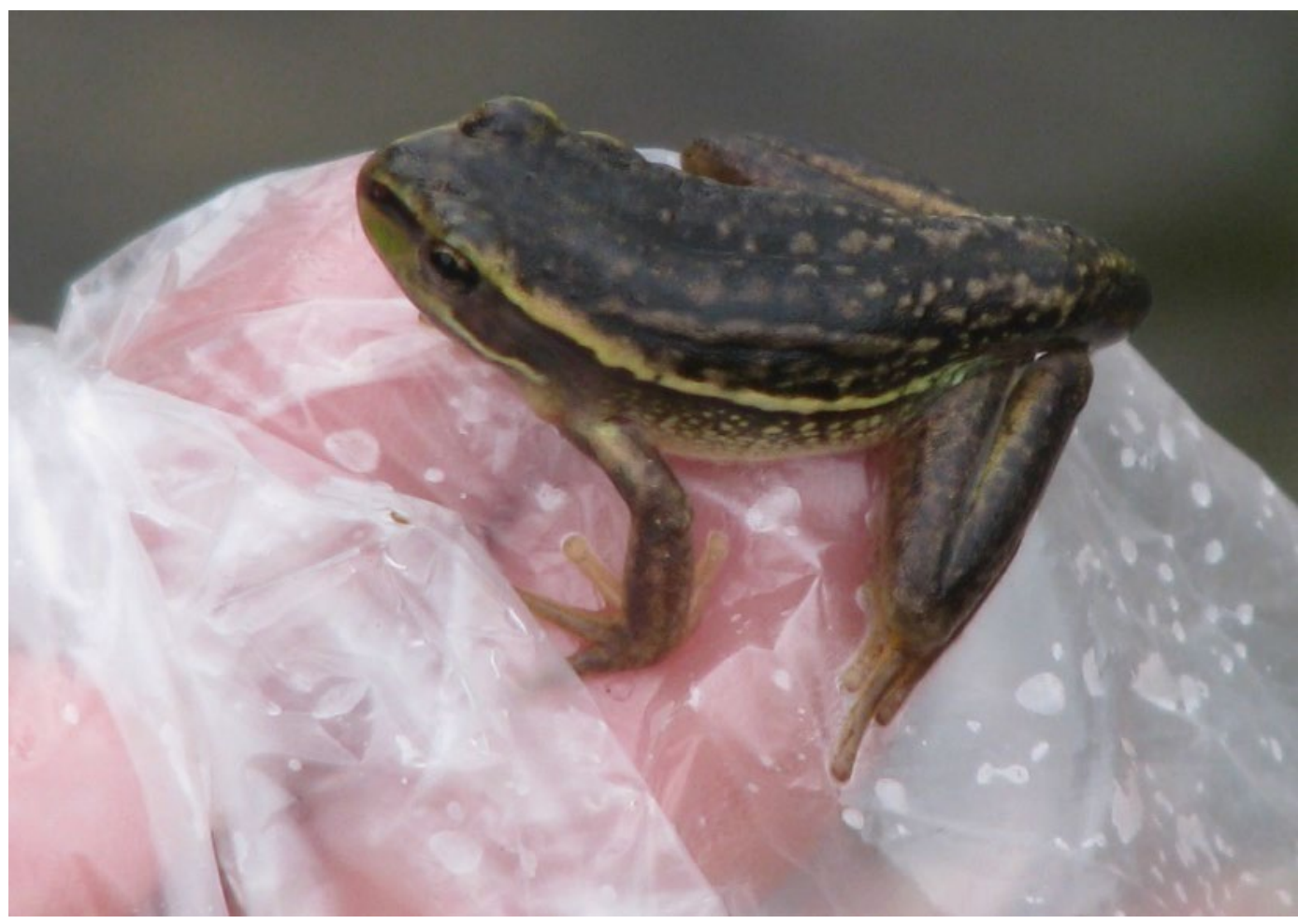

Figure 6 A L. aurea metamorph captured in one of BHP's compensatory habitat ephemeral ponds during monitoring (17 February 2016)

These observations demonstrated that both of the primary KPIs used to measure the establishment of a $L$. aurea breeding population, and the establishment of a viable $L$. aurea population, were met during the 2015-2016 L. aurea breeding season.

Key monitoring observations recorded during the following 2016-2017 L. aurea breeding season included: 
- Mature L. aurea adults were present in the aquatic and riparian habitat within nine of the 11 constructed ponds, for extended periods during the season. An image of an adult $L$. aurea captured during the 2016-2017 L. aurea breeding season is included as Figure 7.

- Calling by adult males and the presence of gravid females was confirmed for extended periods during the season.

- Confirmation of multiple (10) L. aurea breeding events was obtained within five of the 11 constructed ponds, with the observations of $L$. aurea egg masses, tadpoles and metamorphs.

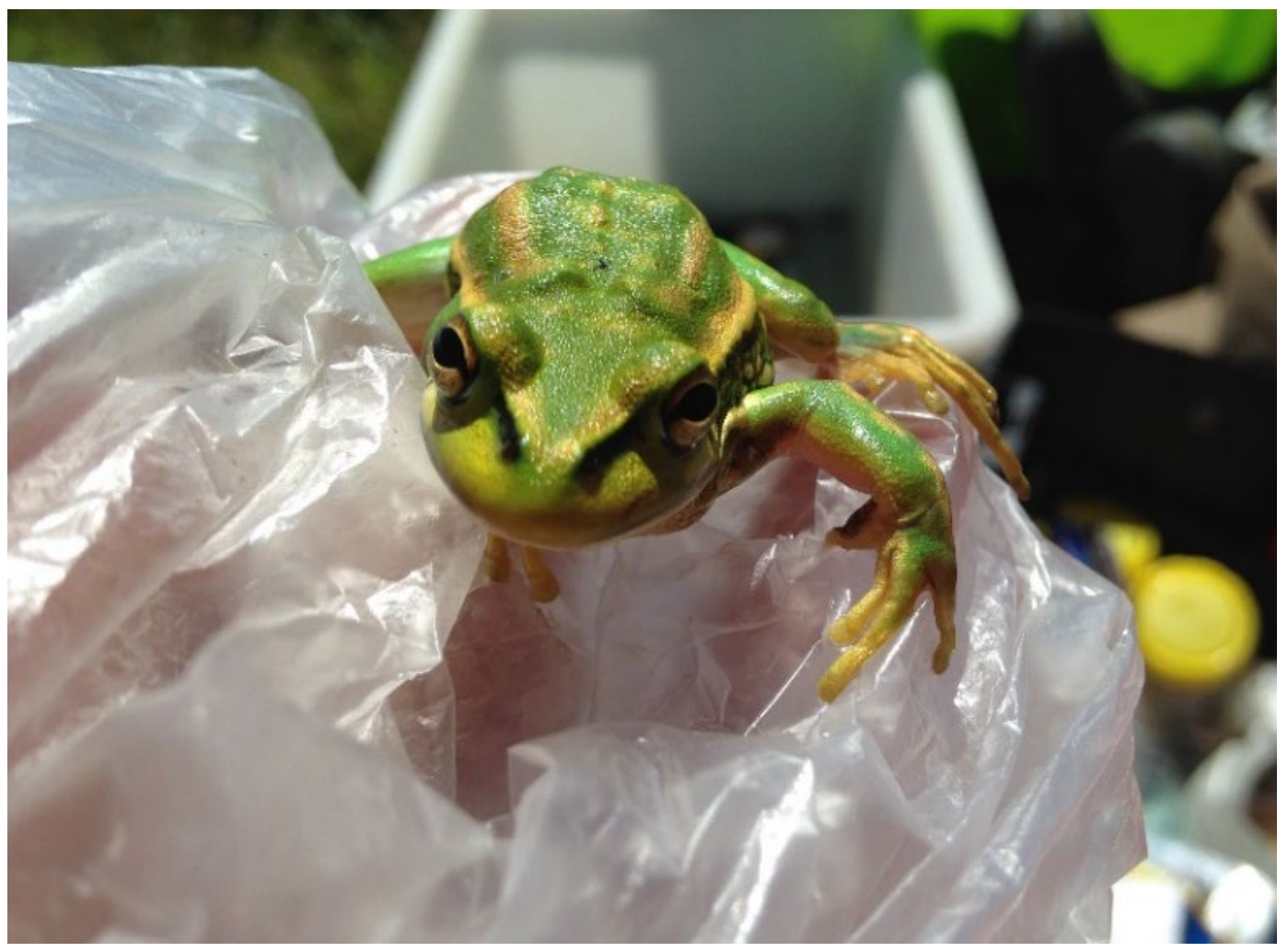

Figure 7 A L. aurea adult captured in an ephemeral pond during monitoring (3 November 2016)

These observations demonstrated that both of the primary KPIs used to measure the establishment of a $L$. aurea breeding population, and the establishment of a viable $L$. aurea population, were met during the 2016-2017 L. aurea breeding season.

The attainment of both of the primary KPIs during each of the 2015-2016 and 2016-2017 breeding seasons constituted the full attainment of both primary KPIs within two distinct seasons, and validated the successful creation of compensatory habitat. Formal acknowledgement of BHP's attainment of both primary KPIs was obtained from NSW and Commonwealth regulatory authorities during 2017.

Notwithstanding the attainment of primary KPIs, monitoring and management of BHP's L. aurea compensatory habitat continues in accordance with BHP's CHP obligations. Multiple L. aurea breeding events have been recorded during subsequent 2017-2018 and 2018-2019 L. aurea breeding seasons, with L. aurea breeding having been recorded in eight of the 11 compensatory habitat ponds since their construction, and the number of $L$. aurea observed during surveys continues to grow, year on year.

BHP's L. aurea compensatory habitat is a dynamic environment with many variables, therefore one can only postulate as to the factors contributing to its sustained success. Regardless, it is evident that the incorporation of key learnings from the $L$. aurea R\&M program into the $L$. aurea compensatory habitat design has optimised the probability of success, namely the creation of habitat which facilitates (generally) maintenance of water quality within defined parameters; pond diversity (ephemeral and permanent) and associated water retention; and perimeter bunding controls to minimise the risk of $G$. holbrooki colonisation. 


\section{Conclusion}

Through the completion of the HRRP, BHP were able to successfully remediate and relinquish residual legacy environmental liabilities associated with contamination to riverbed sediments adjacent to the former Newcastle Steelworks.

Regulatory approval of the HRRP did however necessitate the creation of a further trailing liability in the form of a 25 year CHP for the L. aurea, further demonstrating the challenges associated with attaining relinquishment of residual environmental and other liabilities post-closure of heavy industry. However, there is an end point (i.e. at 25 years with continued success achieved and key targets met) which is often not the case, with instead an absent or unclear path to relinquishment agreed with key stakeholders before closure works start.

Notwithstanding, BHP has been able to transform this 'liability' into a successful outcome for L. aurea, via the conservation, to the extent practical, of habitat within the emplacement facility disturbance area; and the successful establishment of a breeding and viable $L$. aurea population within compensatory habitat created.

The undertaking of comprehensive research and engagement of subject matter expertise during planning phases, mitigation of key environmental risks in design, and the embedding of associated controls during operation/execution, is critical to limiting the potential for departure from any closure plan. Tangible benefits include the reduction of complexity and associated time frame and costs of obtaining regulatory approvals, and ultimately the engineering of a sustainable path to relinquishment of environmental and other liabilities post-closure.

\section{References}

Australian Government 1999, Environment Protection and Biodiversity Conservation Act 1999, https://www.legislation.gov.au Australian Government Department of the Environment and Energy 2019, viewed 23 March 2019, https://www.environment.gov.au Mahony, M 1999, 'Review of the declines and disappearances within the bell frog species group (Litoria aurea species group) in Australia', in A Campbell (ed.), Declines and Disappearances of Australian Frogs, Environment Australia, Canberra, pp. 81-93. NSW Government 2016, Biodiversity Conservation Act 2016 No 63, https://www.legislation.nsw.gov.au

NSW Government Office of Environment \& Heritage 2019, viewed 23 March 2019, https://www.environment.nsw.gov.au Stockwell, MP 2011, Impact and Mitigation of the Emerging Infectious Disease Chytridiomycosis on the Endangered Green and Golden Bell Frog, PhD thesis, The University of Newcastle, Newcastle.

The Department of Environment and Climate Change 2007, Management Plan for the Green and Golden Bell Frog Key Population in the Lower Hunter, Sydney.

White, AW \& Pyke, GH 1996, 'Distribution and conservation status of the Green and Golden Bell Frog Litoria aurea in New South Wales', Australian Zoologist, vol. 30, no. 2, pp. 177-189.

White, AW \& Pyke, GH 2008, 'Frogs on the hop: Translocations of green and golden bell frogs Litoria aurea in greater Sydney', Australian Zoologist, vol. 34, no. 3, pp. 249-260. 
